\title{
FERRAMENTAS DIGITAIS E USO DAS TECNOLOGIAS DA INFORMAÇÃO E COMUNICAÇÃO (TICS) EM TEMPOS DE ENSINO REMOTO NA PANDEMIA
}

\author{
Analice Ferreira Santana ${ }^{1}$ \\ Cleziane Ameida Silva² \\ Janete Silva da Cunha Adorno ${ }^{3}$ \\ Maria Cristiane Silva ${ }^{4}$
}

\begin{abstract}
RESUMO
A pandemia do novo coronavírus mudou o modo de vida das sociedades em todo o mundo. Com as medidas restritivas para conter a crise sanitária, o isolamento social se tornou realidade e o ensino remoto se mostrou uma saída para a continuidade dos estudos da população. Com professores e alunos distantes e conectados, improvisou-se rapidamente uma nova forma e educar, com o apoio das ferramentas digitais das Tecnologias da informação e comunicação (TICs). O objetivo deste estudo consiste em analisar o uso de tais ferramentas no ensino remoto, verificando os aspectos positivos e lacunas ou prejuízos. A metodologia utilizada foi a revisão de literatura, onde diversos artigos foram encontrados, utilizando-se apenas os que focaram no uso das TICs e ferramentas digitais para ensino remoto em tempos de pandemia. Deve-se ter em mente que a educação não será mais a mesma após essa intervenção. Ao experimentar as tecnologias na educação, novas ferramentas e ideias deverão surgir e uma nova forma de aprendizado se abre como possibilidade, que é o aprendizado no universo digital. Os desafios são muitos e envolvem aspectos variados, como a qualidade as tecnologias, o acesso igualitário, a resistência de alguns professores ao uso das TICs e a falta de treinamento técnico e ético para o uso das tecnologias.
\end{abstract}

Palavras-chave: Ferramentas digitais. TICs. Ensino Remoto. Pandemia.

\section{ABSTRACT}

The new coronavirus pandemic has changed the way of life of societies around the world. With the restrictive measures to contain the health crisis, social isolation became a reality and remote teaching proved to be a way out for the continuity of population studies. With distant and connected teachers and students, a new way of educating was quickly improvised, with the support of digital tools of Information and Communication Technologies (ICTs). The aim of this study is to analyze the use of such tools in remote learning, verifying the positive aspects and gaps or losses. The methodology used was a literature review, where several articles were found, using only those that focused on the use of ICTs and digital tools for remote learning in times of pandemic. It should be kept in mind that

\footnotetext{
1 Mestranda em Ciências da Educação pela Faculdade Interamericana em Ciências Sociais(FICS). Licenciada em Geografia pela Universidade Católica do Salvador (UCSAL). Especialista em Educação de Jovens e Adultos pela Faculdade de Pedagogia de Afonso Cláudio. Especialista em Educação Ambiental à Distância pela Universidade Federal da Bahia (UFBA). Email: analice197f@gmail.com

2 Mestranda em Ciências da Educação pela Faculdade Interamericana em Ciências Sociais (FICS). Graduada em Pedagogia (Ucsal). Pós-graduada em Educação de Jovens E Adultos (FAAC). Email:cleziane.ane@gmail.com

${ }^{3}$ Mestranda em Ciências da Educação pela Faculdade Interamericana em Ciências Sociais (FICS.) Graduação em Pedagogia pela Universidade Federal da Bahia (UFBA.) Local de trabalho: prefeitura municipal de Dias D'Ávila. Email:janete.cunha85@gmail.com

${ }^{4}$ Mestranda em Ciências da Educação pela Faculdade Interamericana em Ciências Sociais (FICS). Pós-graduada em Metodologia do Ensino da Língua Portuguesa (UNIASSELV), Pós-Graduada em Estudos Linguísticos e Literários pela Universidade Cândido Mendes. Graduação: Licenciatura em Geografia- Universidade Católica do Salvador_UCSAL.Pós Graduação_ Mídias na EducaçãoUniversidade Estadual do Sudoeste da Bahia- UESB.Pós Graduação- Educação AmbientalFaculdade Afonso Claudio-FAAC. Email:crismaissilva@gmail.com
} 
education will not be the same after this intervention. When experimenting with technologies in education, new tools and ideas will emerge and a new way of learning opens up as a possibility, which is learning in the digital universe. The challenges are many and involve different aspects, such as the quality of technologies, equal access, the resistance of some teachers to the use of ICTs and the lack of technical and ethical training in the use of technologies.

Key-words: Digital tools. ICTs. Remote Teaching. Pandemic

\section{INTRODUÇÃO}

Ao final do ano de 2019 e início do ano de 2020, a pandemia do novo coronavírus mudou o modo de vida das sociedades em todo o mundo. O Brasil já passa por medidas restritivas para conter a crise sanitária desde março de $2020 \mathrm{em}$ todas as áreas, inclusive na educação. Com o isolamento social, as aulas em todo o país, na rede pública e privada, passaram a ser feitas no molde de ensino remoto. Com professores e alunos distantes e conectados, improvisou-se rapidamente uma nova forma e educar, contando com o apoio da tecnologia.

Observando esse contexto e considerando as Tecnologias da Comunicação e Informação (TICs) como um dos inevitáveis elementos centrais desse processo, surge a motivação do presente estudo. Diante desse cenário, emerge a pergunta problema: como as ferramentas digitais de TICs têm interferido no desenvolvimento do ensino remoto em tempos de pandemia? O objetivo geral consiste em analisar o uso de tais ferramentas no ensino remoto, verificando os aspectos positivos e lacunas ou prejuízos. Os objetivos específicos são aqui apresentados, sejam eles: realizar fundamentação teórica fixando as necessárias diferenciações entre ensino remoto e Ensino a Distância (EaD), e demais conceitos de compreensão do contexto/situação problema; realizar revisão de literatura em busca das experiências de pesquisadores brasileiros acerca do assunto; analisar, com base nas pesquisas encontradas, o uso das ferramentas digitais, considerando seus aspectos positivos, negativos e fixando recomendações de novas perspectivas para a educação pós isolamento social.

A metodologia utilizada foi a revisão de literatura, onde diversos artigos foram encontrados, utilizando-se apenas os que focaram no uso das TICs e ferramentas digitais para ensino remoto em tempos de pandemia. Não foram considerados artigos envolvendo $\mathrm{EaD}$ e o período dos artigos publicados limitou-se, por questões de atualização, aos anos de publicação 2020 e 2021. Apenas artigos nacionais foram utilizados. 
O tema se mostrou de extrema relevância visto que ainda se pratica o ensino remoto em diversas instituições no país, dado estado de pandemia declarado pela Organização Mundial de Saúde desde o dia 11 de março de 2020. A necessidade da reformulação veloz do formato e dinâmica de ensino-aprendizagem, atingindo todos os níveis de ensino, na rede pública e privada, não poderia ocorrer sem gerar estudos e pesquisas intensas acerca do assunto. Faz-se necessária e relevante a observação de tais publicações e o constante fomento ao debate e ampliação do estudo desse fenômeno na área educacional. Ressalte-se que os motivos são oriundos de crise sanitária mundial, com consequências devastadoras para a vida, saúde e economia e outras estruturas sociais de todo a população mundial, porém, quando se volta o olhar para a educação, é possível ver avanços na persistência e tentativa de remodelagem urgente do ensino buscando a manutenção das atividades educacionais. Os resultados de tais tentativas não podem passar despercebidos, e isto justifica a importância de abordar esta temática. Espera-se que o estudo contribua para o desenvolvimento do leitor de forma proveitosa como contribuiu para os autores.

\section{AULAS COM O USO DE TECNOLOGIA DE INFORMAÇÃO E COMUNICAÇÃO}

Entre o final do ano de 2019 e o início do ano de 2020, após a notificação de um surto na cidade de Wuhan, China, a população mundial iniciou uma jornada de enfrentamento ao novo coronavírus (nCoV), que causa a SARS ${ }^{5} \mathrm{CoV}$, ou Síndrome Respiratória Aguda Grave. A rápida capacidade de contágio do vírus provocou uma pandemia, declarada no dia 11 de março de 2020 pela OMS. As precauções sanitárias recomendadas envolvem a higienização de pessoas, superfícies e ambientes e a redução de contato próximo e aglomerações de pessoas, resultando no necessário isolamento social. Estas medidas de prevenção ao alastramento de tal crise sanitária tornaram as atividades educacionais presenciais inviáveis em todo o mundo. No Brasil, para que não houvesse a suspensão das aulas, o Ministério da Educação autorizou a substituição das aulas presenciais por aulas remotas, com o uso de tecnologia de informação e comunicação (BRASIL, MEC, 2020; Organização Panamericana de Saúde, 2021)

\footnotetext{
${ }^{5}$ SARS -Severe Acute Respiratory Syndrome
} 
Com a nova forma de viver, a mudança drástica e inesperada na educação lidou com uma adaptação acelerada onde sistemas, gestores, discentes e docentes se viram diante de uma realidade nova para a qual não tiveram nenhum treinamento ou preparação. Porém, a criatividade dos docentes e o auxílio fundamental das TICs se caracterizou como o suporte para tal situação (CORDEIRO, 2020).

Cordeiro (2020) descreve com detalhes o cenário:

[...] as adaptações ao mundo digital ocorreram nas redes públicas e nas redes particulares de ensino, através da utilização de aplicativos de videoconferência, redes sociais e até mesmo a adaptação para a modalidade de Educação a Distância (EAD) através da criação de ambientes virtuais de aprendizagem (AVA). Reaprender a ensinar e reaprender a aprender são os desafios em meio ao isolamento social na educação de nosso país.[...] Muitos professores estão trabalhando a mais para planejar suas aulas em formatos digitais e adotar metodologias ativas. As famílias também tiveram que se adaptar à nova realidade, além de cuidar da casa, trabalho remoto (Home office), precisam acompanhar e auxiliar nas atividades prescritas pelos educadores. Algumas famílias estão tendo dificuldades para acompanhar seus filhos, pois muitos continuam trabalhando e não tem experiência em ensinar. Vale salientar que alguns alunos não possuem acesso à internet ou acesso a TV e não estão acompanhando as aulas (CORDEIRO, 2020, p.3).

É de suma importância salientar que o conhecimento e linguagem popular tem dado ao ensino remoto o nome de Educação à Distância e é basilar diferenciálos. O ensino que tem ocorrido através de plataformas online é o remoto, que tem os mesmos princípios da educação presencial e apenas acontece à distância, utilizando-se ferramentas de conexão de rede para, de forma síncrona (ao vivo, em tempo real), serem ministradas aulas. A interação com o professor é a mesma, o calendário, plano de ensino e as disciplinas, apesar de adaptados pela urgência, são os mesmos. Esta forma de ensino se assemelha ao Ensino a Distância (EaD) apenas por ser mediada pela tecnologia (Ibid).

Sobre essa modalidade e ensino, pode-se definir e comentar sua aplicação no momento de pandemia que:

E o termo 'remoto' por sua vez, conforme o Dicionário Online de Português está relacionado a algo que se encontra longe no tempo ou no espaço. Logo, essa forma de ensino foi imposta porque os professores e alunos estão impedidos de darem continuidade às aulas presenciais. $O$ fato de se tratar de um caráter emergencial, fez com que rapidamente o planejamento pedagógico para o ano letivo de 2020 fosse substituído dando lugar a atividades pedagógicas mediadas pela internet, cartilhas e programas de televisão. Tudo isso foi providenciado na tentativa de minimizar os impactos da pandemia na aprendizagem.[..] Sabe-se que o momento atual não dispõe de uma totalidade de profissionais experientes. A maioria, dentro deste processo é inexperiente e todas estas tecnologias são utilizadas como 
um viés instrumental e de testes. Ademais, é de amplo conhecimento da maioria da população do país que as infraestruturas das escolas públicas estão precárias, por além de saber que o currículo da maior parte das instituições não foi pensado para ser aplicado remotamente, o que torna a situação mais complexa (PAULO, ARAÚJO, OLIVEIRA, 2020. p.195,196).

E não se pode deixar que destacar que:

A suspensão das atividades letivas presenciais, por todo o mundo, gerou a obrigatoriedade dos professores e estudantes migrarem para a realidade online, transferindo e transpondo metodologias e práticas pedagógicas típicas dos territórios físicos de aprendizagem, naquilo que tem sido designado por ensino remoto de emergência. [...] na realidade, essa foi uma fase importante de transição em que os professores se transformaram em youtubers gravando vídeo-aulas e aprenderam a utilizar sistemas de videoconferência, como o Skype, o Google Hangout ou o Zoom e plataformas de aprendizagem, como o Moodle, o Microsoft Teams ou o Google Classroom (MOREIRA et al, 2020, p.352).

Por causa da semelhança, popularmente tem se denominado o ensino remoto de Educação à Distância, mas existem diferenças entre esses termos e modalidades. Regulada por legislação específica e com outras características além da distância entre alunos e professores, a Educação à Distância é definida pela Lei de Diretrizes e Bases da Educação (LDB) (BRASIL, 1996) como "a modalidade educacional na qual a mediação didático-pedagógica nos processos de ensino e aprendizagem ocorre com a utilização de meios e tecnologias de informação e comunicação". Conforme a Lei, nessa modalidade, estudantes e professores desenvolvem atividades educativas em lugares ou tempos diversos.

Enquanto no ensino remoto as aulas são gravadas e em geral ocorrem ao vivo, no Ensino à Distância $(\mathrm{EaD})$ a maioria são gravadas, com videoconferências apenas para tirar dúvidas. Os cursos na EaD são 100\% gravados e os discentes não falam diretamente com o professor e sim com um tutor, com quem trocam mensagens e dúvidas. Diferente do ensino remoto, o material não é personalizado e as aulas não têm dia certo para acontecer, como no ensino remoto, onde as aulas acontecem online no mesmo dia que ocorreriam no presencial (SANTOS, 2021).

Esta diferenciação mínima é importante para compreensão de que o EaD é mais estruturado e planejado e não é o que tem sido feito, o que não retira do ensino remoto as suas vantagens, ainda que realizado de maneira emergencial.

\section{FERRAMENTAS DIGITAIS E USO DAS TICS EM TEMPOS DE ENSINO REMOTO NA PANDEMIA}


Os estudos encontrados demonstraram o quão vasta e diversificada se apresenta a questão do uso das ferramentas digitais no ensino remoto na pandemia. Aqui serão mostrados os resultados encontrados por autores diversos, em estudos com modalidades variadas de metodologia, todos observando uso das TICs de forma urgente como resolução e adaptação ao distanciamento social imposto pelo ensino remoto, seja este o único possível em crise sanitária. Todos os artigos encontrados foram redigidos ou publicados nos anos e 2020 e 2021.

O estudo aplicado por Paulo; Araújo; Oliveira (2020) teve por objetivo a análise de discurso de docentes a respeito da experiência do ensino remoto emergencial na pandemia. Foi aplicada entrevista virtual de questionário semiestruturado com 9 professores da Educação Básica da rede pública e privada de ensino do interior de Minas Gerais, através do Google Meet, plataforma que permite reuniões virtuais. Foram observadas diferenças no processo para aderir ao ensino remoto emergencial, onde as escolas públicas demoraram mais para se organizar e enviaram blocos de atividades aos alunos, fazendo uso de Google Meet, Facebook e Whatsapp, havendo, porém, algumas secretarias que limitaram o contato entre professores e alunos.

Nenhuma das escolas da rede pública utilizou plataforma ou ambiente virtual de aprendizagem, o que, segundo os autores, reforça a exclusão social oriunda da exclusão digital, já que acesso à internet e níveis de renda e escolaridade estão diretamente relacionados. Na rede privada, de maneira oposta, as atividades remotas se iniciaram uma semana após o decreto de isolamento social do governo. Porém, na rede pública observou-se contato entre professores e alunos para tirar dúvidas de exercícios através de e-mail, grupos de Whatsapp e até mesmo ligações, aproximando professor, estudante e pais. Foram também relatados usos de livros digitais, sites e atividades de movimento com auxílio das TICs. Para além das dúvidas e atividades, professores relataram retorno afetivo através das ferramentas digitais de comunicação, entre alunos da Educação Básica, que frequentemente utilizavam esses meios solicitando aos pais contato com professores para dizer que sentiam saudades ou que desejavam o retorno às aulas com os colegas.

Com o objetivo de analisar o desenvolvimento do trabalho remoto dos professores de escolas públicas e privadas da cidade e Ji-Paraná, do estado de Rondônia, Alves et al (2020) aplicaram o uso de ferramentas digitais como 
plataformas digitais, sites, e-mails, Google Meet, Google sala de aula, Google Forms, Whatsapp para tirar dúvidas e mesa digitalizadora, observando a função de cada ferramenta, que foram disponibilizadas aos estudantes. Os autores relatam que foi possível observar o quão essenciais são essas ferramentas digitais no período de isolamento social e evidenciaram a necessidade da combinação de algumas dessas ferramentas. Os docentes adaptaram de forma rápida, apesar da necessidade de haver alguns treinamentos específicos. Já os estudantes, precisaram adaptar-se mais aos hábitos de organização pessoal de estudo e disciplina na nova modalidade, do que ao uso das ferramentas em si. A melhor adaptação em relação ao uso das ferramentas se deu no Google Meet e Google Sala de Aula, devido à possibilidade de interação em tempo real.

A pesquisa feita por Costa e Conceição (2021) analisou as implicações do ensino remoto em relação à disciplina de Educação Física. Foram entrevistados 18 professores da rede pública de Ensino Fundamental e Médio do município de Vigia de Nazaré, estado do Pará. Os resultados trouxeram as problemáticas do ensino remoto nesse componente curricular. A falta de estrutura, principalmente na zona rural onde a internet é precária, bem como a falta e conhecimento dos docentes sobre ensino remoto e ensino híbrido, obrigou os mesmos a se reinventarem. Ficou evidente a necessidade de formação continuada e o destaque dos autores para o fato da falta de infraestrutura digital das escolas públicas escancarar ainda mais as desigualdades sociais. As TICs não são vivenciadas de forma igualitária e representam enorme desafio para a comunidade escolar do município, em especial para o componente curricular Educação Física.

Ferreira et al (2020) realizaram pesquisa com 14 professores de matemática dos anos iniciais do Ensino Fundamental, para identificar práticas e recursos pedagógicos no ensino remoto, com foco no uso das tecnologias digitais. Os alunos dos anos iniciais, ainda que tenham facilidade de acesso aos meios digitais, não têm idade suficiente para a adequada incorporação do ensino remoto à sua rotina de estudos, o que se revelou um desafio para seus docentes. A maioria dos docentes entrevistados não possuía formação específica para a área de tecnologia e tiveram que utilizar os recursos digitais do dia a dia adaptando ao ensino e potencializando esses recursos. Os aplicativos de mensagens instantâneas foram utilizados para gravação e envio de vídeos e interação com os alunos. Sites de envios de vídeos 
também foram utilizados. Como resultados os autores destacam a redução de interação virtual com alunos e famílias, o baixo acompanhamento familiar nas atividades e a falta de formação específica para o uso correto e de qualidade das ferramentas digitais na educação em Matemática.

A pesquisa aplicada por Braga, Brescia, Dantas (2021) identificou aspectos relativos ao uso de aparatos tecnológicos e redes de internet por discentes e docentes em Minas Gerais, nos cursos de graduação da UEMG em 2020, da qual participaram 229 professores e 669 alunos. Os pesquisadores destacam que, por conta da pandemia, os entrevistados tiveram que adquirir aparatos tecnológicos que antes não possuíam, para adaptar-se à nova realidade. Porém um ponto ressaltado é que essa possibilidade ocorreu para a maioria dos professores enquanto entre alunos, menos da metade apresentou capacidade socioeconômica para tais aquisições/melhorias. A renda se mostrou como fator preponderante para a decisão e possiblidade das aquisições dos equipamentos/recursos, evidenciando que as desigualdades socioeconômicas influenciam diretamente no uso e desempenho das ferramentas tecnológicas para aprendizado na pandemia. Quanto aos recursos mais utilizados, tanto professores quanto alunos apontaram o uso do Power Point, emails e de ambientes virtuais de aprendizagem. $\mathrm{Na}$ instituição, ficou fixada a escassez dos recursos digitais e instalações inadequadas como um dos motivos da desigualdade de acessos a meios tecnológicos entre alunos e professores.

Outra publicação encontrada envolve o uso de uma ferramenta específica para estratégia de ensino na modalidade remota. Silva Júnior, Silva, Bertoldo (2020) apresentaram o uso do podcast na pandemia sob uma perspectiva pedagógica. A pesquisa apresenta sugestões de uso educativo da ferramenta, onde os autores afirmam encontrar grande potencial pedagógico. As sugestões elencadas são narrações de HQs, criação em grupo de podcasts com gêneros textuais variados (já que os alunos podem realizar essa tarefa mesmo em distanciamento social), criação de podcasts de aulas pelo próprio educador. Os autores destacam que a ferramenta permite melhoria do trabalho com oralidade, instiga a aprendizagem criativa, potencializa o desenvolvimento de competências e habilidades, focados no ensino da língua e perfeitamente aplicáveis no ensino remoto.

Em pesquisa envolvendo 170 professores da educação básica em São Paulo, que estavam desenvolvendo atividades na modalidade remota de ensino, Rondini, 
Pedro e Duarte (2020) abordando docentes da rede pública e privada, fixaram observações diversas a respeito do uso das TICs em ensino remoto. A necessidade de rápida adaptação à nova metodologia, e de estar constantemente conectado, concitando em aumento de jornada de trabalho, além dos impactos negativos das desigualdades socioeconômicas, com comprometimento da interação e aprendizagem, foram observadas na rede pública. Nas escolas privadas, houve sucesso no uso das plataformas por conta de os docentes terem vivência prévia com tais recursos. As dificuldades foram relatadas em relação a disciplinas que exigiam demonstração de situações-problema ou solução de exercícios. A maioria dos professores utiliza recursos muito básicos como Pacote Office, YouTube e Redes Sociais e isto pode afetar a habilidade em situações mais complexas. Um aspecto positivo a ser ressaltado é que a maioria dos entrevistados afirmou ter pretensão de prosseguir com a utilização das ferramentas tecnológicas mesmo após a pandemia.

Uma pesquisa com olhar mais específico, realizada por Lima; Santos; Pereira (2020), observa o uso de mapas mentais digitais no ensino remoto. Os mapas mentais consistem em representações de informação de maneira esquemática, que apresentem conceitos e hierarquia de informações, relacionando fatos, significados, eventos, de forma a estruturar o conhecimento com rapidez e clareza. Essa ferramenta, se feita de maneira digital, apresenta recursos visuais dinâmicos ou não, ainda mais eficazes à sua estrutura. O uso dos mapas mentais online se mostrou positivo e satisfatório, onde os discentes entrevistados demonstraram haver contribuição para o seu processo de aprendizagem com melhor absorção, memorização e síntese. Trata-se, desta forma, de mais uma ferramenta digital específica que pode ser explorada no ensino remoto com êxito.

Uma publicação semelhante feita por Neto et al (2021) tratou do uso dos mapas mentais no ensino de Biologia através da ferramenta digital de criação desses mapas, onde estudantes residentes de Pedagogia do Instituto Federal de Educação, Ciência e Tecnologia do Sul de Minas, utilizaram a ferramenta e relataram resultados promissores, já que a ferramenta demonstrou-se didática e dinâmica, permitindo elaboração de material de estudo coletivo, acompanhamento da discussão e interferência dos docentes, com consequente avanço considerável da aprendizagem. 
Também focados na avaliação do uso de uma ferramenta digital específica, Minuzi, Santos, Barin (2020), apresentaram em relato de experiência aspectos ao uso do Google Classroom para aulas virtuais. Trata-se de uma ferramenta que se constitui em uma sala de aula virtual, que possui formas de construção colaborativa de conteúdos, cujo acesso é gratuito, o uso é facilitado e pode ser utilizada em interfaces diferentes como computador, tablets ou smartphones. Os autores ressaltam que a interface amigável facilita a adesão dos estudantes. Destaca-se também os formulários, a possibilidade de avaliações por rubrica, facilitando feedback e o uso intuitivo da plataforma. A ferramenta se apresentou com um recurso capaz de amenizar alguns prejuízos trazidos pela falta dos encontros presenciais.

Em amplo estudo numa escola em Campo Grande (MS), Cardoso, Cabellero, Rubinho (2020) analisam ações realizadas em uma escola municipal com 1866 alunos e 101 professores, onde as tecnologias foram largamente utilizadas frente à necessidade de isolamento social, principalmente na gestão escolar. São ministradas formações sobre ferramentas tecnológicas com frequência na instituição como parte da rotina, e o destaque é para o uso da plataforma Moodle, ambiente virtual utilizado para sistematizar as ações das organizações de atividades. Os documentos escolares e atividades da escola participante da pesquisa são geridos e realizados através desse AVA, o que demonstra excelente proveito de uma ferramenta gratuita e acessível. Os autores recomendam a continuidade do atendimento remoto nas escolas municipais, já que este viabiliza o acesso de professores e alunos, não apenas na pandemia, mas como inovação permanente da localidade e Campo Grande.

Moreira e Dunel (2021) realizaram pesquisa qualitativa, exploratória e experimental na Universidade Federal da Bahia, em uma turma de Desenho Técnico com conteúdo teórico prático, onde diversas ferramentas de TICs foram utilizadas na estruturação da disciplina na pandemia, de forma integrada, trazendo um suporte positivo durante o curso. Cientes do potencial e especificidades de cada ferramenta, os autores afirmam que o potencial de rendimento dos alunos na disciplina foi bem aproveitado. Ficaram destacados como pontos positivos a melhoria do atendimento dos professores para sanar dúvidas e a assertividade no seu compartilhamento com a ajuda da tecnologia. As ferramentas Google Forms, Socrative e Jamboard 
trouxeram organização, melhoria e acesso e feedback, além de melhor entendimento do aluno. Como pontos negativos, problemas de conexão e ausência de contato pessoal, além da negativa por parte de alguns alunos em compartilhar suas imagens já que não possuíam ferramentas tecnológicas para participação satisfatória. A visualização dificultada de atividades de desenho em tela e sua correção foi um aspecto negativo envolvendo a dificuldade de atuação dos professores. Os autores salientam, ainda, a eficácia da utilização de ferramentas pertencentes a uma mesma plataforma e utilização da TICs de maneira mais integrada.

Os artigos encontrados apresentaram soluções diversas para o período de aulas remotas e demonstraram a utilização das ferramentas digitais de TICs tanto em termos gerais quanto de forma específica, focada em apenas uma ou duas ferramentas. Trata-se de uma diversidade de formas proveitosas de lidar com o ensino remoto, já prevendo algumas das situações adversas aqui descritas.

O capítulo a seguir analisa os resultados e discute as informações encontradas nos estudos.

\section{ANÁLISE DOS ARTIGOS SOBRE USO DA TECNOLOGIA NAS AULAS}

É interessante destacar que na maioria dos artigos encontrados os professores não possuíam treinamento prévio para uso da tecnologia em suas aulas, o que sempre dificultou sua aplicação. A rápida adaptação é também algo presente na maior parte dos estudos, assim como a evidenciação das diferenças socioeconômicas, que ficam mais à vista quando é necessário ter boa conexão de internet e equipamentos tecnológicos em casa, que são recursos não acessíveis a pessoas de baixa renda no Brasil. Certamente tais estudantes (e até mesmo alguns professores) se viram excluídos de processos diversos nesse período por falta desses recursos e as escolas não tiveram capacidade de fornecer suporte satisfatório.

Outro aspecto observado é a facilidade com que se transforma ferramentas de uso social e cooperativo em ferramentas para a educação. Muitas das ferramentas específicas mencionadas são utilizadas para exposição de conteúdos de entretenimento, interação social ou trabalho, e tiveram que ser adaptadas ao 
ambiente e objetivo educacional, o que demanda criatividade e improviso inteligente por parte de discentes e principalmente dos docentes.

A facilidade dos alunos para com a tecnologia, pelo largo uso de celulares, é um ponto positivo e que certamente ajudou no progresso da interação tecnológica, porém essa facilidade não é capaz de contemplar a habilidade e disciplina necessárias a uma rotina de estudos online. Muitas vezes o aluno pode não ter idade e, portanto, maturidade para esse modo de aprendizado, ou, quando o tem, está dividindo o ambiente do lar em isolamento social com seus pais e/ou familiares, tornando mais difícil a tarefa de concentrar-se para os estudos em um ambiente onde se está morando, trabalhando e cuidando ao mesmo tempo. Os lares se transformaram quanto ao seu uso e isso certamente envolveu o aprendizado em casa.

A presença dos pais mostra-se também fundamental, no contato com os professores e no acompanhamento e suporte para o dia a dia das aulas e tarefas, no caso dos níveis de ensino Fundamental e Médio. É importante compreender também que nem todos os pais têm facilidade ou tiveram acesso com ferramentas digitais desde criança, como os filhos e isso pode gerar dificuldades no contato e acompanhamento.

Deve-se ter em mente que a educação não será mais a mesma após essa intervenção. Ao experimentar as tecnologias na educação, novas ferramentas e ideias deverão surgir e uma nova forma de aprendizado se abre como possibilidade, que é o aprendizado no universo digital.

Os desafios são muitos e envolvem aspectos variados, como a qualidade as tecnologias, o acesso igualitário, a resistência de alguns professores ao uso das TICs e a falta de treinamento técnico e ético par o uso das tecnologias.

\section{CONSIDERAÇÕES FINAIS}

O uso das tecnologias na educação pode ser de grande proveito e estímulo à nova geração de alunos, aos professores e aos novos modos de vida necessários nos tempos atuais. É importante que o estudo das ferramentas digitais seja aprimorado com foco na educação, para que mais ferramentas voltadas para a área sejam desenvolvidas, sem a necessidade e adaptação de ferramentas de outros 
campos. Porém, deve-se compreender que a boa adaptação das ferramentas já disponíveis é também eficaz.

A atualização constante dos docentes se faz necessária. Atualmente, mais do que nunca, ser docente é estar conectado, em todos os sentidos. O educador deve ser um entusiasta da tecnologia, promovendo o seu bom uso na educação e fora dela, em tempos onde as TICs trazem tantos prejuízos devido à imensa e desenfreada interação social na internet. A tecnologia deve ser uma aliada, pois ela pode tornar o aprendizado mais plural e autônomo. Ainda assim, o ensino remoto não deve substituir o presencial. As experiências educativas online jamais serão comparadas ou suficientes quanto a vivência no espaço acadêmico e escolar, para professores e alunos.

\section{REFERÊNCIAS}

ALVES. G.P.R et al. Ferramentas digitais face a pandemia da covid-19; percepções didáticas a partir da vivência de professores da educação básica em Rondônia. XIV Seminário Nacional de Literatura, História e Memória e V Congresso Internacional de Pesquisa em Letras no Contexto Latino Americano. 2020.

BRAGA, B. S.; BRESCIA, A.T.; DANTAS, D.M.P. Acesso e uso de aparatos tecnológicos e internet na educação superior em Minas Gerais. Minas Gerais: Scielo. Scientific Electronic Library Online. 2021.

BRASIL. Lei de Diretrizes e Bases da Educação Nacional, LDB. 9394/1996.

BRASIL, MINISTÉRIO DA EDUCAÇÃO. MEC autoriza ensino a distância em cursos presenciais. Publicado em: 18 mar. 2020. Disponível em: <http://portal.mec.gov.br/busca-geral/12-noticias/acoes-programas-e-projetos637152388/86441-mec-autoriza-ensino-a-distancia-em-cursos-presenciais > Acesso em: 01 dez. 2021.

CARDOSO, P.S.F.; CABELLERO, C.F.F.; RUBINHO, V.S. Tecnologias digitais e inúmeras possibilidades de aprendizagem. Integra EaD 2020. Educação e Tecnologias Digitais em cenários de transição: múltiplos olhares para a aprendizagem. Campo Grande, MS. 2020.

CORDEIRO, K. M.A. O impacto da pandemia na educação: a utilização da tecnologia como ferramenta de ensino. Faculdade IDAAM, Amazonas, 2020. Disponível em: <http://idaam.siteworks.com.br/jspui/bitstream/prefix/1157/1/O\%20IMPACTO\%2 ODA\%20PANDEMIA\%20NA\%20EDUCA\%C3\%87\%C3\%830\%20A\%20UTILIZA\%C3 \%87\%C3\%830\%20DA\%20TECNOLOGIA\%20COMO\%20FERRAMENTA\%20DE\%2 OENSINO.pdf. > Acesso em: 02 dez. 2021. 
COSTA, W.C.P.; CONCEIÇÃO, W.L. Educação Física Escolar no contexto pandêmico no Município de Vigia de Nazaré no estado do Pará. Research, Society and Development, 2021.

FERREIRA, L.A., et al. Ensino de matemática e COVID-19: práticas docentes durante o ensino remoto. Universidade Federal de Pernambuco. Pernambuco: Revista de Educação Matemática e Tecnologia Iberoamericana, 2020.

LIMA, A.C.B; SANTOS, D.C.M.; PEREIRA, A.P.S. Mapas Mentais e conceituais como ferramentas para a aprendizagem significativa no ensino remoto. Integra EaD 2020. Campo Grande: Educação e Tecnologias Digitais em cenários de transição: múltiplos olhares para a aprendizagem, 2020.

MINUZI, N.A; SANTOS, L.M.A.; BARIN, C.S. O uso de ferramentas digitais na mediação para o ensino remoto. Goiância, GO. CIESUD, 2020.

MOREIRA , L. C. de S. .; DUNEL , M. P. . Tecnologias da informação e comunicação integradas ao ensino remoto emergencial. In: Simpósio Brasileiro de Tecnologia da Informação e Comunicação na Construção, 3., 2021, Uberlândia. Anais [...]. Porto Alegre: ANTAC, 2021. p. 1- 11. Disponível em: $<$ https://eventos.antac.org.br/index.php/sbtic/article/view/598> Acesso em: 3 dez. 2021.

MOREIRA, J.A.M.; HENRIQUES, S.; BARROS, D. Transitando de um ensino remoto emergencial para uma educação digital em rede, em tempos de pandemia. São Paulo: Dialogia, 2020.

NETO, A. B. et al. Educação em tempos de pandemia: ferramentas digitais utilizadas durante o ensino remoto. Educação em Foco. Instituto Federal Sul de Minas Gerais.

ORGANIZAÇÃO PANAMERICANA DE SAÚDE. Coronavirus. 2021. Disponível em: <https://www.paho.org/pt/topicos/coronavirus> Acesso em: 01 dez. 2021.

PAULO. J.R.; ARAÚJO, S.M.M.S.; OLIVEIRA, P.D. Ensino remoto emergencial em tempos de pandemia: tecendo algumas considerações. São Paulo: Dialogia, 2020.

RONDINI, C.A.; PEDRO, K.M.; DUARTE, C.S. Pandemia da covid-19 e o ensino remoto emergencial: Mudanças na prática pedagógica. Interfaces Científicas, 2020.

SANTOS, W.J.B. Um olhar sobre o ensino remoto na base da Scielo. Trabalho de Conclusão de Curso. Licenciatura em Ciências Biológicas. Universidade Federal de Campina Grande: Cuité, PB. 2021

SILVA JUNIOR. E.A.; SILVA, C.F.P.; BERTOLDO, S.R.F. Educação em tempos de pandemia: o uso da ferramenta podcast como estratégia de ensino. Tecnia,2020. 